\title{
A percepção da mudança: os registros na cidade de Goiás
}

\section{The perception of change: the records in the city of Goiás}

\section{Adriana Mara Vaz de OLIVEIRA*}

Resumo: Este artigo discute a relação existente entre acontecimento e indivíduo, na perspectiva de uma história das sensibilidades. Parte-se do pressuposto de que as expressões a respeito dos fatos ajudam a elucidá-los. O acontecimento eleito é a transferência da capital goiana, na década de 1930, avaliado a partir das manifestações dos moradores da antiga sede administrativa, registradas nos periódicos de circulação local. A mudança do centro de poder da Cidade de Goiás para Goiânia provoca reações aos destituídos dessa condição, que demonstram o ressentimento pela perda, mas também resignação e otimismo pela criação de alternativas ao desfecho consolidado. Diante de tais registros, verifica-se a forma urbana da Cidade de Goiás como elemento de confrontação às percepções expostas.

Palavras-chave: Cidade de Goiás. Percepção. Periódicos.

\begin{abstract}
This paper discusses the relationship that exists between events and individuals from the perspective of a history of sensibilities based on the assumption that the manner in which facts are related assists in their clarification. The event selected for analysis is the transference of the capital city of Goias State in the 1930s. This is evaluated through the testimony of residents of the prior seat of administration, sourced from contemporaneous reports in local newspapers. Moving the Goias' power center from the City of Goias to Goiania caused a general outcry which not only revealed resentment for the city's loss, but also resignation and optimism concerning the creation of viable alternatives for a universally satisfactory outcome. Through the analysis of such records, the city’s urban form itself may be seen as confronting elements of the perceptions expressed within.
\end{abstract}

Keywords: City of Goiás. Perception. Newspapers.

\footnotetext{
*Professora doutora em História (Unicamp) do Curso de Arquitetura e Urbanismo da Faculdade de Artes Visuais da Universidade Federal de Goiás, Universidade Federal de Goiás, Faculdade de Artes Visuais. Campus II Samambaia 74001-970 - Goiania, GO - Brasil - Caixa-Postal: 131 Telefone: (62) 35211127. E-mail: amvoliveira@uol.com.br
} 


\section{Considerações iniciais}

O Álbum de Fotografias sobre o Planejamento e Construção da Cidade de Goiânia, de 1935, oferecido pelo então governador goiano Pedro Ludovico Teixeira ao presidente da República, Getúlio Vargas, demonstrava, com propriedade, os discursos vinculados à mudança da capital do Estado. As fotos encardidas da cidade de Goiás escondiam-se atrás da pujança das obras da moderna Goiânia. A outrora Vila Boa era apresentada como se estivesse congelada no tempo e ressaltando aspectos pacatos e rurais - ruas sem calçamento, cavalos e carroças perambulando pelos espaços públicos -, em uma demonstração de vínculos indissolúveis com os séculos anteriores. Goiânia, ao contrário, era mostrada como ícone da modernidade, por meio da sua arquitetura sem adereços historicistas, do campo de pouso com o avião da Vasp, das ruas pavimentadas, das alamedas retilíneas arborizadas, entre outros. (Figuras 1 e 2).

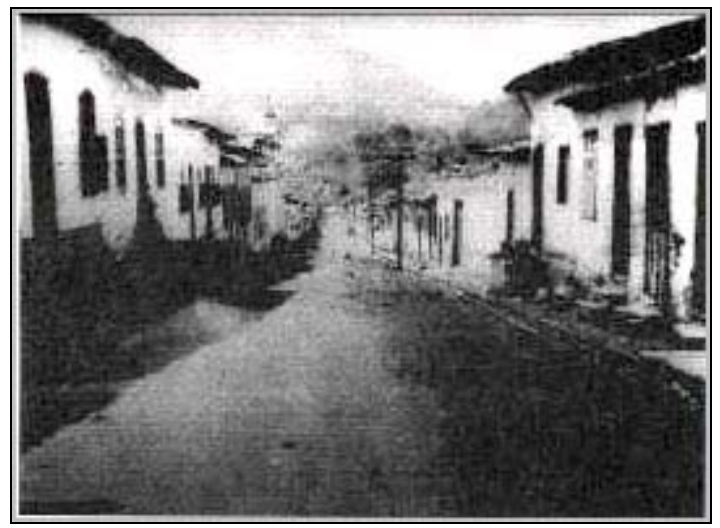

Figura 1 Rua Cidade de Goiás. Fonte: CUNHA NETO, 1995.

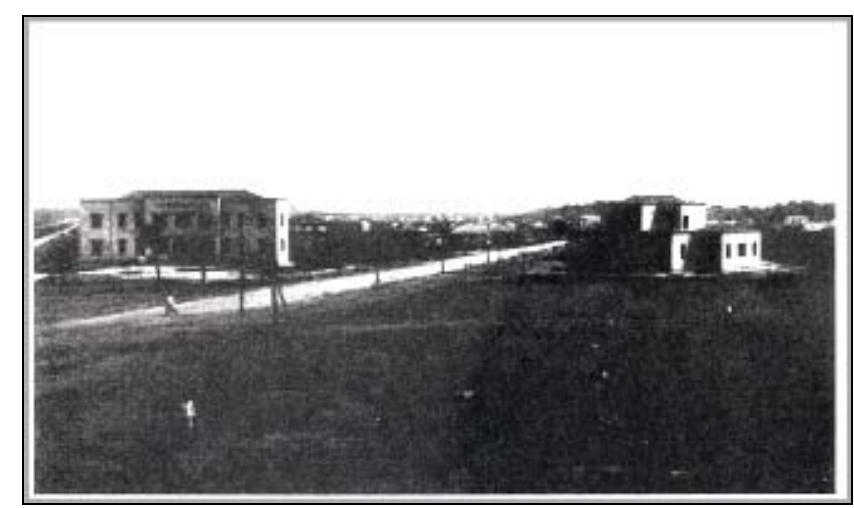

Figura 2 Rua de Goiânia. Fonte: CUNHA NETO, 1995.

A imagem perpetuada do sertão - identificado com o atraso e preso ao meio rural - colavase à Cidade de Goiás, ao contrário de Goiânia, que era a porta para o mundo moderno e urbano. Diante de tal álbum, o presidente enchia seus olhos de esperança e se orgulhava da interiorização do território brasileiro, constatando que o impossível poderia acontecer. Bastavam ousadia e parcerias bem-sucedidas, como no caso goiano.

Pedro Ludovico Teixeira consolidou o sucesso dessa parceria na edificação da sua metrópole. Esse personagem, assim como a sua cidade, suscitou vários estudos de reconhecido mérito. A interlocução da política varguista com a saga médica de Ludovico encontrou aporte nos 
planos urbanos de Attílio Correia Lima e Armando de Godoy, tornando-se objeto de interesse recorrente das pesquisas em torno de Goiânia.

Os estudos historiográficos do limiar do século XX para ali se dirigiram, porque lá se concentrava o turbilhão moderno em oposição à decadência e ao atraso de Goiás nos séculos anteriores. No sentido inverso, apenas no final da década de 1990, aparecem estudos como o de Gomide (1999), que investigou a antiga capital no período de 1930 a 1978, a partir das imagens dicotômicas a ela relacionadas: por um lado, a de atraso e degradação e, por outro, de preservação e berço da cultura goiana. A sua intenção percorria a construção de um discurso patrimonial, em que se elegia a cidade de Goiás como histórica, ainda no rescaldo da mudança. Em um caminho semelhante, encontra-se também a pesquisa de Delgado (2005), que discute a invenção de Goiás como patrimônio nacional e, posteriormente, mundial, apoiada na articulação de grupos da comunidade local.

Assim, a maioria dos estudos representa a euforia dos vencedores ou daqueles que acreditavam no progresso aclamado com a nova capital e pouco foi observado sobre os clamores dos céticos e destituídos moradores do antigo núcleo urbano, exceto os autores há pouco mencionados.

Contudo, os oposicionistas ao governo estadual e os temerosos da sua frágil condição se manifestaram nos periódicos locais, constituindo-se em fontes privilegiadas para a percepção dos sentimentos de derrota e ressentimento. Essas manifestações traduzem-se em relatos que discorriam sobre os aspectos materiais da cidade destronada, a indignação dos que ali permaneceram, o descrédito ao novo projeto do governador, a confiança na palavra ludoviquista de não esquecê-los, e o enaltecimento da cultura e tradição dos vilaboenses como o apelo ao seu brio diante do vazio.

Nesse âmbito, o presente artigo compatibiliza-se com a vertente da historiografia que busca a sensibilidade na história, ou seja, compreende que as manifestações humanas, quaisquer que sejam, permitem percursos na construção histórica, assim como o fez Baudelaire ao exprimir as suas emoções diante das transformações parisienses. Não se trata aqui de dar voz a um único personagem, mas compreender o conjunto das manifestações veiculadas pela imprensa, por meio do corpo editorial dos periódicos ou dos moradores da cidade, expressas nas suas declarações e atitudes.

Como disse Pesavento, “a sensibilidade se expressa como uma forma de reação dos sentidos, através de emoções de sensações, dada pelo contato do indivíduo com a realidade” (2006, p. 161). Nesse caso, a realidade é a perda do status de capital de Goiás e tudo aquilo a ele ligado. O dado objetivo da mudança acarreta sentimentos e ressentimentos que somente são revelados pela 
avaliação de fontes adequadas, que, nesse caso, encontram-se nos periódicos e nas marcas da cidade.

\section{Cidade de Goiás: a modernidade acanhada}

A ruralização da população goiana após o declínio da mineração já foi muito discutida, assim como a constatação de que essa circunstância acompanhou todo o processo de ocupação do território até o século XX, em complementaridade a sua urbanização. O caráter complementar entre o urbano e o rural da ocupação territorial goiana desmistifica a visão da historiografia tradicional em ressaltar apenas o seu viés civilizador ou urbano. Desse modo, a capital de Goiás, no início do século XX, trazia encarnações do passado, como vivências do presente, repletas de ruralidade, reforçadas pela ausência de nexos com a economia nacional.

As expressões dessa complementaridade podiam ser observadas na morfologia da cidade e de seus edifícios, assim como nas suas práticas políticas. A cidade de Goiás era um núcleo urbano que se configurava diante de suas raízes portuguesas - ruas sinuosas e adaptadas à topografia, casas coladas umas às outras numa homogeneidade contínua, igrejas e edifícios oficiais destacados em largos irregulares -, expressas na sua vernaculidade, somada à simplicidade e à lentidão do ritmo de vida, baseada nas relações com o meio rural.

Do mesmo modo, o poder político assentava-se no papel da cidade como centro administrativo, em consonância com o fortalecimento das oligarquias agrárias, que ali se faziam representar, ainda que se distribuíssem em algumas localidades do território goiano.

Na década de 1930, em função das lutas políticas anteriores, a cidade condensava o status de atraso por representar as oligarquias depostas. Naquele momento, ao assumir o governo de Goiás, o médico Pedro Ludovico Teixeira assimilou o discurso moderno varguista e empreendeu uma campanha a favor da construção de uma nova capital para o Estado. Como esclarece Chaul:

A modernidade para os arautos de 30 consistia no progresso do Estado, por meio do desenvolvimento da economia, da política, da sociedade e da cultura regionais. [...] a representação da modernidade se edificava em oposição ao passado que encarnava a decadência e o atraso de Goiás ao longo de sua história. (CHAUL 1997, p. 149).

A intenção foi concretizada em 1937, com a transferência definitiva para Goiânia, símbolo da modernidade ou progresso em Goiás.

A partir daí, Goiânia assume os holofotes e a Cidade de Goiás cai no ostracismo esperado. Afinal, a modernidade almejada vinha pelos trilhos do trem, mas materializava-se na cidade de ruas 
largas e arborizadas, por meio de suas construções art déco. O asfalto substituía a pedra, assim como o tijolo ocupava o lugar do adobe e o carro atropelava o cavalo. (Figuras 3 e 4).

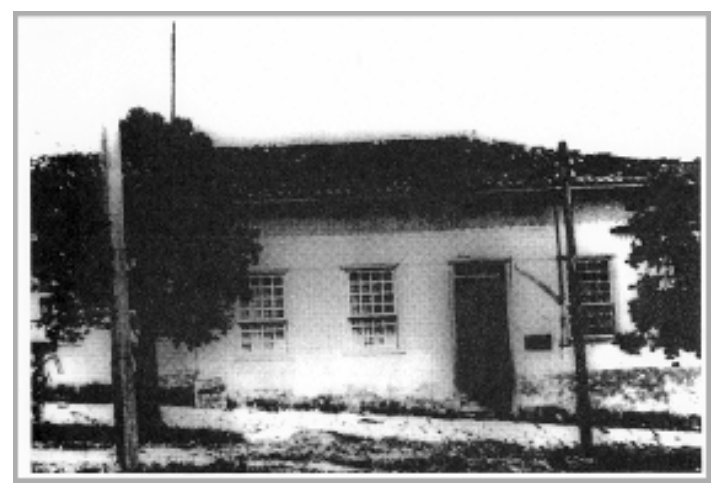

Figura 03 Correios, Cidade de Goiás. Fonte: CUNHA NETO, 1995.

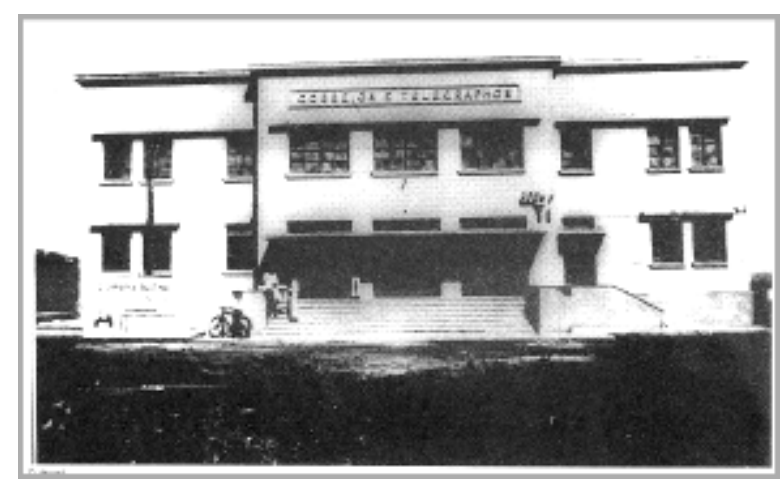

Figura 4 Correios, Goiânia. Fonte: CUNHA NETO, 1995.

Apesar da presença do passado e da sombra do futuro, a Cidade de Goiás demonstrava sincronia e pertencimento ao limiar daquele século, por meio de exemplares arquitetônicos ecléticos, ainda que singelos; de intervenções na infraestrutura urbana - como a instalação de luz elétrica e canalização de água -; da existência de equipamentos urbanos como o Mercado Público (1857), o Cemitério (1859), o Gabinete Literário (1864), e outros; da circulação de ideias e produtos, possibilitados pelos jornais e comércio; da vigência das posturas urbanas municipais consoantes com as de outros locais do país. Nesse sentido, por exemplo, a criação da Repartição de Hygiene do Estado de Goiás, em 1909 (OLIVEIRA, 2001) demonstrava as preocupações dos administradores acerca da salubridade pública e a atualização das ações locais. Todavia, essas atitudes administrativas que estiveram presentes no século XIX e adentravam mansamente pelo século XX submetiam-se ao inexpressivo papel que Goiás ocupava na federação brasileira.

Nos anos de criação de Goiânia, os periódicos ressaltavam os investimentos e as obras na cidade, mostrando as atitudes da administração municipal em contraposição ao governo estadual:

Prefeitura de Goiás - Cel. Joaquim Bastos

Abastecimento de agua no mercado publico por meio de eletricidade Instalou mais duas caixas dagua e separou o abate de suínos Fora da cidade estão levantando três bairros novos para classe pobre mas com construções distintas.

Isenção de impostos municipais todas as mercadorias vindas do Araguaia.(O SOCIAL, 16 fev. 1934, n. XXIII).

Melhoramentos urbanos

A phase de transformações porque vae passando a nossa capital, devido ao seu natural desenvolvimento, tem encontrado da parte do actual prefeito, sr. Cel. 
Joaquim da Cunha Bastos, já não dizemos uma equivalência de esforços, mas uma actividade incessante que chama logo a attençao de todos.

Mal termina uma obra de importância, e muitas vezes ao mesmo tempo, se inicia outra, tudo feito numa agitação febril, que só se observa nos grandes centros.

Assim, em poucos dias, tivemos o alargamento e o nivelamento da Praça da Prefeitura, a construcçao do caes que fica fronteiro, o alargamento da rua da Carioca, o entupimento da rampa próxima à Ponte Nova, os concertos da rua Marechal Abrantes, o aformoseamento e o calçamento da praça do Palácio e, ainda agora, o calçamento da praça do Rosário, alem de muitos outros que seria longo enumerar. (VOZ DO POVO, 4 mar. 1934, n. 319).

A ênfase recaía sobre as ações corriqueiras, e exaltava-as. Essa valorização era personificada na pessoa do prefeito coronel - um indicativo de que era um grande proprietário de terras -, que apontava para a possibilidade da sobrevivência urbana, mesmo após a mudança. No entanto, as obras mostravam a dimensão dos problemas urbanos, que não eram diferentes daqueles dos séculos anteriores, sugerindo a precariedade nos investimentos públicos. Nesse sentido, a sugestão extrapolava o âmbito político e aproximava-se do econômico, o que o governo estadual tentava reverter com a inserção do Estado no circuito desenvolvimentista brasileiro.

Coetâneos às ações em torno da nova capital, os periódicos destacavam alguns indícios de vida moderna na antiga Vila Boa, como a abertura de novos bares, hotéis e casas comerciais, proclamando o avanço em direção ao progresso. A propaganda do Hotel Portugal, veiculada no jornal Cidade de Goyaz (n. 75), de 10 de março de 1940, informava disponibilizar água corrente em todos os quartos, bebidas nacionais e estrangeiras, além de uma grande Frigidaire para os hóspedes. (Figura 5) Esses atrativos equiparavam as estruturas urbanas tradicionais àquelas na nova cidade, alardeada nos anúncios do Grande Hotel (Figura 6):

Grande Hotel de Goiânia

O melhor no gênero, em todo o Brasil Central.

Construído sob o mais rigoroso plano de arquitetura moderna.

Confortável - higiênico

Panorama admirável

Horizontes magníficos

De suas sacadas o turista poderá contemplar, em toda sua plenitude, essa luta ciclópica entre um povo que vai construindo sua cidade e a natureza virgem, travada em uma das mais encantadoras paragens do "Hinterland" brasileiro. Duelo imponente em que a mão do homem apenas aumenta a beleza verdadeiramente edênica da paizagem. Mixto de cidade e de sertão.

Visitai Goiânia, a caçula das capitais brasileiras e hospedai-vos no Grande Hotel

Diária 15\$000 e 20\$000. (CORREIO OFFICIAL, 19 fev. 1937, n. 3370). 


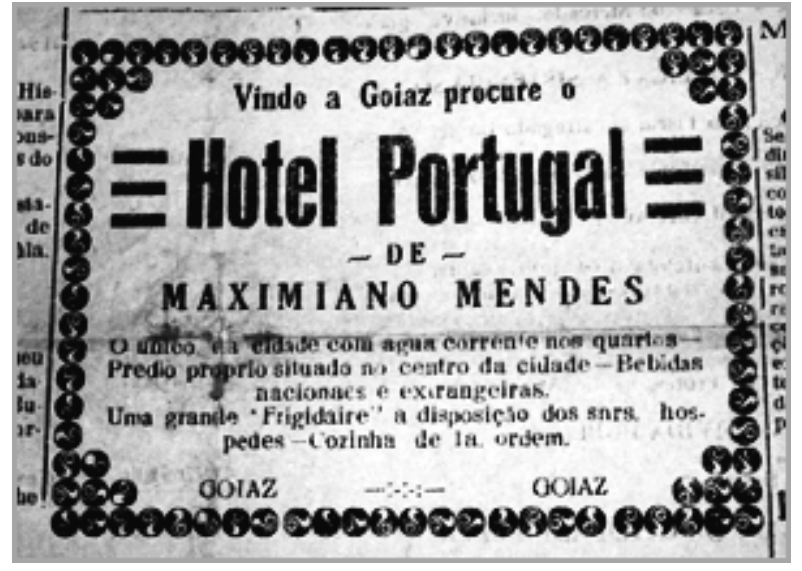

Figura 5 - Anúncio Fonte: Jornal Cidade de Goiaz, 1940.

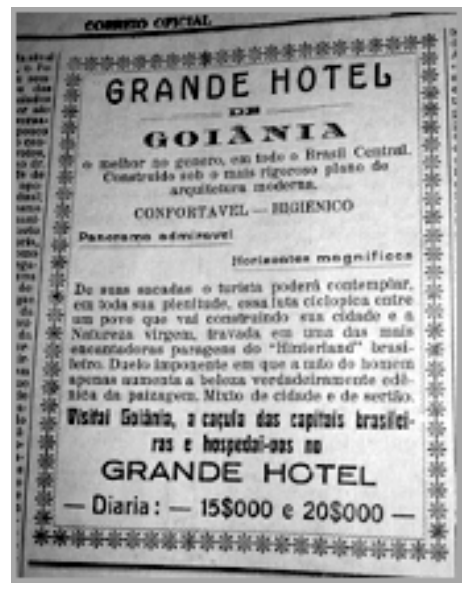

Figura 6 - Anúncio Fonte: Correio Official, 1937

Nota-se que o apelo contido na publicidade do hotel goianiense extrapolava o uso do edifício e suas vantagens e ingressava no discurso da modernidade e do progresso, traduzido na luta entre homem e natureza. Para a Cidade de Goiás, a modernidade traduzia-se em pequenos feitos como o abastecimento de água ou a geladeira, e respondia, ainda que precariamente, à modernização do lugar.

Com a nova capital ainda em construção, a cidade destituída divulgava aquilo que a distinguia como a vida cultural, traduzida na programação dos cinemas e nos novos bares que difundiam alegria entre os habitantes, como mostram os anúncios que seguem:

Cine Theatro Goyano

Esta elegante casa de diversão exibirá, hoje, o formidável filme da METRO "SUZAN LENOX"

Com a linda Greta Garbo e Clark Gable, artista já querido da platéa goyana. [...] (CIDADE DE GOIAZ, 19 jun. 1938, n.1).

Hoje no Cine-Progresso

O maior filme da Paramount, a soberana

"A mulher faz o marido"

Com Charles Rugges e Mary Boland

Não percam. (CIDADE DE GOIAZ, 19 jun. 1938, n.1).

Casa de Milton

Goiaz indiscutivelmente está avançando. E muito. 
Construções novas surgem, estabelecimentos comerciais e industriais se inauguram, e o progresso está chegando de verdade. Agora é o Sr. Milton da Rocha Lima que está construindo, no centro da cidade, um belo edifício para a instalaçao de sua forte casa comercial. [...]. (CIDADE DE GOIAZ, 19 jun. 1938, n.1).

Além da Casa de Milton, inaugurava-se o Bar e Sorveteria Central, que imprimia a nota chic da cidade, com “salões barborinhantes” de uma “assistência selecionada”, por possuir “maquinário novo”, “ambiente confortável e moderno” (CIDADE DE GOIAZ, 19 jun. 1938, n.1). Da mesma forma que as obras urbanas, esses sintomas eram brandos e reforçavam a tentativa de aproximação da antiga capital com as intenções do governo estadual.

A publicidade era completada por artigos que reforçavam a hombridade dos vilaboenses, corroborando a ideia da resistência da vida urbana. Ao contrário da derrota, a ressurreição materializava-se na reforma das casas, no avivamento do comércio, na intensidade da vida cultural, enfim, nos sinais já apontados.

\section{Cidade de Goiaz - João Perillo}

O surto animador de vida e de trabalho que se vem fazendo notar em todos os ramos de atividade humana da cidade de Goiaz constitue, hoje, para nós outros, motivo de um orgulhoso e comovido registro.

Bem ao contrário das perspectivas sombrias e desalentadoras que lhe toldaram, ontem, a existência, a nossa cidade, numa ressureiço magnífica de energias, num soerguimento moral e material, vem de traçar os seus próprios destinos destacandose na vida coletiva do Estado, como uma de suas melhores e futurosas unidades.

Há em tudo uma palpitação de fé que se renova; um avivar de esperanças que alentam e um desejo nobre e patriótico de realizações que se objetivam.

As casas vão sendo, aos poucos, remodeladas, modificando a ossatura singela da cidade. O comercio mostra-se cada vez mais movimentado e florescente. Nas suas praças ajardinadas, nos cafés, nos cinemas, nas ruas, nota-se desde logo esse movimento buliçoso, característico das cidades que progridem, índice de alegria, de trabalho e de civilização humana. Surgem novos bars, alegrando a fisionomia sertaneja da terra cabocla.

[...]

O amor e o otimismo do nosso povo, alicerçando a vida da cidade, desmentiram cabalmente a opinião apressada dos que profetizaram o aniquilamento e a decadência de Vila Boa. Ela aqui está de pé e viva, carregando sobre os ombros, remoçados dous séculos de tradições dignas e honrosas!

[...]. (CIDADE DE GOIAZ, 19 jun. 1938, n.1).

A importância desses indícios diminuiu diante do discurso do convencimento à resistência que tentava alcançar os moradores da Cidade de Goiás, destronados após dois séculos como centro do poder regional. Passados alguns anos do início da edificação de Goiânia, os registros da sobrevivência urbana da Cidade de Goiás confirmavam que o parâmetro a ser seguido, a partir de então, vinha da luta entre homem e natureza como transformação, exemplificado pela jovem capital, e não mais como subtração, como havia sido a sua consolidação no passado aurífero. 


\title{
Promessas para o futuro: os primeiros anos de mudança
}

\author{
Goyaz \\ Marie Joseph
}

Eu visitei cidades seculares, Que a arte, sem cessar, torna famosas; Vi seus templos, as torres, campanários; De seus reis, as moradas sumptuosas; Paris - cidade-Luz, cujo esplendor Centro do mundo a fez, para os vindouros Como hoje e sempre; Roma, onde ao Senhor Se offerecem ephemeros thesouros....

Vi Londres, a brumosa! Vi Berlim, Florença... Vi a Ponte do Suspiro, Stockholmo, Madrid.... Até que, enfim, Vi a linda Goyaz, cuja belleza Soube doar-lhe dona Natureza. Sim! É Goyaz que a todas eu prefiro [tradução do francês]. (VOZ DO POVO, 2 jun. 1933, n. 281).

Comparar a Cidade de Goiás a outras expressivas cidades do mundo significava enaltecer o brio de seus habitantes. O jornal situacionista sabia disso e, por meio de Marie Joseph - ou seria Maria José -, cotejou-a com Paris, Berlim, e mesmo Florença, que erroneamente servia de cenário para a Ponte do Suspiro. O objetivo era elevar a autoestima da sua população, após a irrevogável decisão de Pedro Ludovico. O poema iniciava uma batalha entre os que apoiavam a mudança e aqueles que a condenavam.

De um lado, o Estado e seus defensores empenhavam-se em amenizar o transtorno da transferência, criando alternativas para a cidade, ao mesmo tempo em que conclamavam o apoio de todos. O relatório do interventor Pedro Ludovico, de 1932 alertava para a impossibilidade de adequar aquele núcleo urbano aos novos tempos, a transferência do poder como premissa para o crescimento do Estado. As dificuldades de inserção daquela cidade ao esperado mundo moderno decorriam da sua posição geográfica e seu sítio, que impossibilitava o abastecimento de água, a ligação com outros centros por meio de transporte ferroviário, a higienização de suas casas e ruas, tudo isso desfavorecido pelo clima, entre outros (CORREIO OFFICIAL, 12 dez. 1933, s.n). As assertivas apontavam com clareza a impossibilidade de a Cidade de Goiás ocupar a centralidade exigida para as novas metrópoles, não diferenciando dos argumentos utilizados na mudança da capital de Minas Gerais, que, por sua vez, remetiam ao pensamento saint-simoniano (LEPETIT, 2001). 
Contudo, o duro discurso de Ludovico veio acompanhado de outros que propunham a superação das dificuldades da cidade existente e, ao mesmo tempo, a defesa da sua empreitada mudancista. Para isso, propôs a formação de um batalhão militar, o incentivo ao comércio no rio Araguaia, extensão da linha ferroviária, estradas rodoviárias e estímulo à vinda de colonos, como aponta o artigo:

Ideia opportuna

O Sr. Dr. Pedro Ludovico, a par de sua idéia de remover a sede do Governo para uma cidade moderna e construída a propósito, quer cumprir a solenne promessa feita à Velha Villa Boa onde tem S.Excia. e os demais inexoráveis próceres, enterrados os seus preciosos cordões umbelicaes.

A promessa feita é a de deixar aqui algumas centelhas de progresso ou algum signal de vida e incentivos.

A vinda e estacionamento de um batalhão [...] está dependendo apenas da reparação do quartel. [...]

Outro beneficio é o de dotar a navegação do Araguaya com uma lancha movida a motor e com capacidade para 30 toneladas de carga. [...].

Ora, a população da Capital com boas estradas para as pontas dos trilhos e para o porto de Leopoldina, com um batalhão estacionado em Villa Boa e esperançosa do crescente povoamento do município com o advento de colonos agricultores, constituídos de milhares de famílias, que venham habitar e cultivar nossas uberrimas terras, cessará por certo de cobrir de anathemas e maldiçoes os próceres do mudancismo. Todas as classes serão beneficiadas por esses meios de desenvolvimento e expançao às suas actividades especiaes.

Esta paragem não há de ser para sempre um chão parado, uma terra proscripta e abandonada como malssinam os pessimistas e os que não enxergam tantas riquezas e possibilidades em condições de serem exploradas com vantajosos resultados; por que Villa Boa há de sempre disputar a primazia em tudo quanto aprouve ao Creador presentear ao homem como matéria prima do melhor quilate para o edifício de seu bem estar e de sua prosperidade.

Demos pois o devido valor ao que possuímos e não descreiamos do nosso grandioso futuro.(VOZ DO POVO, 16 abr. 1933, n. 277).

Em meio a essas manifestações de apoio e convicção num futuro melhor, aparecem outras que enveredam pela seara da negatividade e apostam no fracasso da mudança. Nos periódicos oposicionistas o tom era o inverso, pois se propagavam a falência do governo e o malogro de Goiânia.

No ano de 1934, o jornal dirigido por Alfredo Nasser da Coligação Goiana - um grupo antimudancista que unia o Partido Libertador e o Partido Democrata -, iniciou sua campanha contra a transferência da capital, com um artigo, supostamente escrito por uma mulher, que afirmava crer no abandono da cidade após a mudança:

Depois dos brilhantes artigos publicados na "Colligação" mostrando com implacável realidade a situação de tapera em que ficará reduzida Villa-Bôa, escrever mais nesse assunto é supérfluo. Entretanto devemos voltar insistentemente 
a elle, afim de que os villaboenses, convençam-se que votar na chapa do governo é querer a sua própria ruína, é ver suas casas cobertas de trepadeiras "S. Caetano", como dizia que havia de ver, quando a mudança se realizasse, o illustre clinico que foi o seu maior propagandista. [...]. Villa-Bôa, a cidadezinha que já foi o encanto do velho bandeirante, será um dia, realizando-se a mudança, um punhado de ruinas. [...]. (A COLLIGAÇÃO, 30 set. 1934, n. 6).

Observa-se que o convencimento passa pelo voto e a imagem invocada é a de ruína. Como tal, "evoca um passado glorioso e a caducidade de todas as coisas, [...] [mas] pode dar lugar a um sentimento subtilmente crepuscular” (CARENA, 1984, p.107). Por meio de suas palavras, a autora deixa transparecer a certeza de um futuro sombrio para a cidade, pois as ruínas, tanto pessoais como materiais, eram marcas históricas na paisagem, evidenciando a transitoriedade de tudo, inclusive daquela esperança. O encanto pela cidadezinha foi conferido ao bandeirante, que ali só parou porque encontrou ouro e de lá saiu quando este findou. Sobre o mestiço colonizador e agricultor nada mencionou, porque seria inferir responsabilidade àquele que destoa da modernidade. $\mathrm{O}$ bandeirante, por sua vez, trazia a verve da coragem e da descoberta, tão necessárias ao progresso.

Na continuidade dos ataques à mudança, o jornal A Colligação escrevia em letras destacadas notícias como “OS 2.458 CONTOS NÃO SÃO PARA O PROLONGAMENTO DA E.F. GOYAZ E SIM PARA A VARIANTE DE BULHÕES A CAMPINAS!” ( 30 set. 1934, n. 6), e completava, na edição seguinte, com um artigo que, assim como o analisado acima, também se intitulava “Mudança da Capital”:

Causou grande sensação nesta capital a nota oficial transcrita no último numero desta folha sobre o verdadeiro destino dos celebres 2.458 contos que o Correio Oficial, em telegrama do Rio, disse serem para o prosseguimento da E.F.de Goyaz. [...]. Os 2.458 contos tem uma finalidade clara: a construcçao de uma variante que, partindo de Bulhões, vai ter a Campinas. E se é verdade que nas estradas de penetração os núcleos surgem nas pontas de linha e florescem e vivem enquanto os trilhos não caminham, é meridiano que o interesse maior do governo seja paralisalo nos arredores da nova cidade, impedindo que ela tenha o mesmo destino de, por exemplo, Roncador e Vianopolis. Anápolis, que já tem a sua estação, não ouvirá o silvo da locomotiva. Assim Inhumas, Itaberahy, Villa Boa que ficarão completamente fora de qualquer cogitação. [...] a vitória do governo significa a hecatombe de Villa Boa. (A COLLIGAÇÃO, 4 out. 1934, n.7).

As denúncias concentravam-se no desvio de verbas e na consequente alteração no percurso da ferrovia, que privilegiava a nova capital em detrimento da antiga. Essa modificação era emblemática, porque asseverava a posição do interventor em concretizar o seu sonho.

De acordo com o editor Alfredo Nasser e os redatores do jornal oposicionista, as ações demeritórias relacionavam-se aos recursos financeiros do Estado e alardeavam que "a transferência 
da sede do governo para Goyania vae ser o começo do fim. A ultima etapa da derrocada geral da insolvabilidade, do descalabro financeiro!” (A COLLIGAÇÃO, 29 set. 1935, n. 41).

Pouco tempo depois, no mesmo periódico, apareceram reivindicações para aumento de salários dos funcionários do governo transferidos “forçadamente” para a nova capital. Para que isso fosse atendido, vociferavam que os custos seriam transferidos para a população goiana ao dizer: “Não bastam os temporaes que tem cahido, acompanhados de raios. Vêm, agora, novos impostos p’ra cima do povo!” (A COLLIGAÇÃO, 13 out. 1935, n. 42).

Para os contrários à mudança, o extravio de investimentos na cidade bandeirista conduzia a sua destruição. Os discursos demonstravam rancor e ressentimento diante dessa situação e clamavam: "votar nos candidatos do PSR nas próximas eleições é entregar a Cidade de Goiaz aos seus destruidores” (A COLLIGAÇÃO, 10 nov. 1935, n. 45). Proclamavam-se ações contra o assolamento da antiga capital e reclamavam o desamparo governista, conforme artigo que segue:

\section{Contra a destruição de Vila Boa}

Foi apresentada à Assembléia Legislativa um projeto de lei concedendo favores aos operários, residentes nesta capital, e queiram se mudar para Goiânia.

Defendendo os interesses da cidade de Goiaz, tão prejudicada pela campanha mudancista, os deputados Jacy de Assis e Alfredo Nasser, na Comissão de Justiça, regeitaram o projeto, proferindo o seguinte voto:

Um dos motivos de combate à mudança da capital [...] foi o desamparo da cidade de Goiaz, condenada à estagnaçao e sem medidas de proteção e de garantia de sua vida e de seu progresso.

[...] ele pretende é o aliciamento, o seu afastamento, a criação de dificuldades à vida de Goiaz, cada vez mais arrastada ao abandono.

Este projeto não tem nenhuma finalidade social, e nem demonstra simpatias a causa do operariado; sua finalidade é aniquilar as últimas energias da cidade abandonada com a obra mudancista, com o afastamento até dos seus operários.

Ate esta data, a assembléia não recebeu, por parte do Governo, uma só iniciativa que prove seu interesse pela proteção de Vila Boa; a mudança se está operando a custa dos últimos dinheiros públicos, sem um gesto de amparo a esta cidade. [...] (A COLLIGAÇÃO, 10 nov. 1935, n. 45).

No mês seguinte, a partir da saída de Pedro Ludovico da Cidade de Goiás, o mesmo jornal alterou seus pressupostos de ataque, em que as lamentações pela destruição do antigo núcleo urbano foram substituídas pelo descrédito a Goiânia. Os arroubos de frustração proclamavam a dissolução de Goiânia antes da sua concretização: “O povo que fique tranqüilo: a transferência da sede do executivo é uma tentativa que fracassará como as outras!” (Id, 8 dez. 1935, n. 47). E completam:

A sede do poder executivo Inesperadamente, sem se despedir dos amigos mais íntimos, o Dr. Pedro Ludovico Teixeira transferiu-se desta capital para Goiânia, levando consigo a sede do poder executivo. 
Entre os mais graduados e influentes membros do situacionismo o desapontamento era tão grande, que nenhum delles procurou atenuar com desculpas, a evidente desconsideração. [...].

Há de voltar a estes ermos o sr. Pedro Ludovico Teixeira. O que S. Excia imagina em vias de realização, é apenas obra mal começada. Goiânia jamais será a capital de Goyaz. Uma cidade se edifica com dinheiro e dinheiro não existe. A teimosia que já levou o estado à fallencia, vai leval-o a catastrophe. [...](A COLLIGAÇÃO, 8 dez. 1935, n. 47).

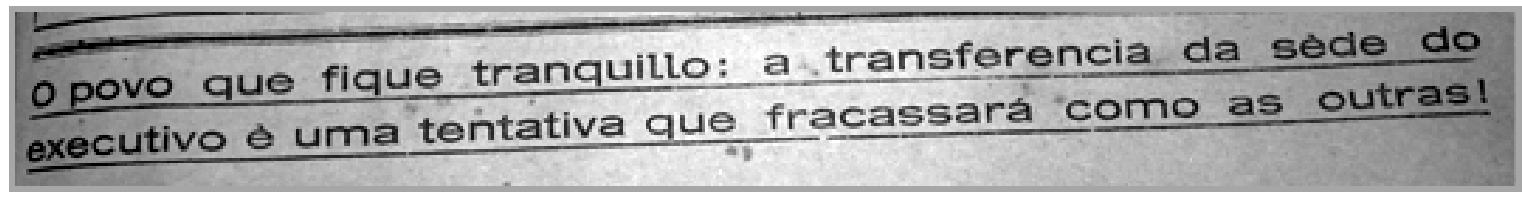

Figura 7 - Texto em destaque.

Fonte: Jornal A Colligação, 1935.

Pedro Ludovico mudou-se para um pequeno núcleo urbano nas imediações do local onde Attílio marcava com ossos de ema (MELLO, 2006) o traçado da cidade que semeava nos sertões: Campinas. A sua atitude assegurava o processo de transferência, pois deslocava a administração do Estado antes mesmo da conclusão das obras da nova capital. Essa conduta certificava o abandono da antiga Vila Boa, gerando ressentimento daqueles que ficaram ou dos que foram contra a vontade.

Muitas vezes, o ressentimento era manifestado por meio da ironia. Em um artigo intitulado “Fazendo cidades”, de autoria de Aladim, “sem a lâmpada”, segundo a escrita do jornal, compara-se Ludovico a Napoleão e Goiânia a Nova York.

O Governo do Estado resolveu hibernar nas imediações de Campinas, onde, segundo consta, vae construir uma cidade.

Conta-se que Napoleão Bonaparte passou a história com o mais terrível fabricante de reis que o mundo já viu.

O grande corso fazia um monarcha com a mesma facilidade que promovia um cabo de esquadra a sargento.

Para o Governo de Goyaz, porém, o “petit caporal”é café dos menores.

Os actuaes dirigentes do Estado passarão à história como os maiores "fazedores" de cidades de que esse buraco de mundo já teve notícia.

É certo que a mentalidade retrograda de certos sujeitos super-carcomidos anda a assoalhar não ser possível, com uma renda oneradissima de 6 mil contos, construirse uma New York nos cerradoes de Campinas.

Possibilissimo!

[...]

Qual! Assim não há tatu que possa construir esta cidadezinha.

[...](A COLLIGAÇÃO, 19 dez. 1935, n. 48).

Após ironizar o projeto de construção da nova metrópole, a oposição sacraliza seu aniquilamento, pois que reduzida a apenas dois edifícios. Em três anos, aos olhos agourentos dos 
oposicionistas, muito pouco havia sido feito em Goiânia, o que alimentava o sonho de um fracasso e do retorno à Cidade de Goiás.

A cidade de Campinas é hoje por um decreto considerada arrabalde dos dois prédios na nova capital. O governo quer com isso justificar a permanência das repartições no velho e gasto casario da terra de José Rodrigues. Tentativa inútil! O povo já sabe que a construcção da "metrópole”fracassou. Goiânia não passara de dois prédios. O executivo vae ficar mesmo em Campinas temporariamente. Depois regressará ao ninho antigo nesta Villa Boa. [...]. (A COLLIGAÇÃO, 4 jan. 1936, n. 49).

Essas impressões eram propagadas por aqueles que ficaram e tinham sido destituídos do poder. O ressentimento e o descrédito eram marcas possíveis de serem averiguadas nas suas falas. Afora a amargura do abandono, os “sobreviventes” tentavam encontrar uma saída, que já havia sido sugerida, mas não trabalhada. A partir da constatação da irreversibilidade da situação com a concretização de Goiânia, os vilaboenses se apegaram à tradição e vislumbraram a possibilidade de renascimento.

\section{Inovas a tradição: a saída digna}

Para os moradores da Cidade de Goiás, as notícias vindas de Goiânia eram as piores possíveis. Ao contrário do que vaticinaram os jornais oposicionistas, a metrópole do cerrado, enfim, vingava. Os apelos ludoviquistas deram resultado e em poucos anos a cidade ia se formando. Era um caminho sem retorno.

Para contrabalançar os ataques advindos dos periódicos que defendiam o fracasso do novo centro urbano, outros jornais começaram a circular em Goiás, editados na nova Capital, que divulgavam o sucesso da empreitada governista. Assim como os exageros dos periódicos contrários à construção da cidade, o Jornal Goiânia também carregava nas nuances desenvolvimentistas da recém-criada cidade.

Goiânia desenvolve-se dia a dia

Quinze dias ou um mez de ausência da actual capital goyana, basta-nos para verificar o intenso existente em nossa futura metrópole.

Dezenas de casas se constroem não somente em Goiânia, como em Campinas, de modo que em breve, ligadas ficarão.

Vários omnibus percorrem as ruas levando e trazendo passageiros. O commercio cresce, numeraram-se as ruas, abaularam-se as artérias, movimentam-se os bars, hotéis e pensões, constroem-se dez casas, para operários, em 15 dias, um palácio para a Câmara dos Deputados, em um mez.

Assim é Goyania - a grande, a futurosa metrópole dos goyanos. (GOIÂNIA, 11 jun. 1936, n. 3). 
O jornal Correio Official, outro veículo de comunicação do governo estadual, já produzido em Goiânia, também a promove e informa: “Goiaz numa fase de progresso intensivo. A nova capital do Estado já é um centro de civilização” (CORREIO OFFICIAL, 9 jan. 1937, n. 3360). Como já se prenunciava, Goiânia era vista como a porta de entrada de Goiás à modernidade. Os trilhos dos trens anunciaram essa possibilidade, mas a cidade materializava a inserção. Tudo ali cheirava a modernidade: construções sem telhados aparentes, trabalhadores de vários lugares do país, máquinas abrindo ruas e transportando materiais e pessoas, enfim, indícios que rompiam com a morosidade dos tempos de isolamento e atraso. Tempos que a Cidade de Goiás tão bem representava, mas que já não interessava. Logo, era necessário encontrar uma alternativa que garantisse o seu lugar na história, mesmo que a partir de então o turbilhão da modernidade a ditasse.

Em meio aos ataques, assim como aos louvores, à recente cidade, esboçavam-se as alternativas para a antiga Vila Boa: a história e a tradição. Na publicação oficial do Estado esse caminho despontou, como mostra o artigo abaixo:

Goiaz, cidade tradicional - Guimarães Lima

$[\ldots]$

Não conheço Goiaz. Admiro-a profundamente, apezar disso. Sei que é uma cidade eminentemente culta. Daí, então, o direito de fazermos esta trilogia comparativa: Paris é a terra dos tumultos; Londres a metrópole dos nevoeiros; Goiaz, a cidade da instrucção. [...]. Goiaz e Goiânia dão-se mãos para o progresso vertiginoso da pátria de Anhanguera. Elas se entendem e se estimam. Porque, se Goiânia é filha do patriotismo, Goiaz é filha da tradição!

[...]

Efetivamente Goiaz como as nossas primitivas cidades, não foi construída de acordo com os planos de urbanização. Não obstante a isso, ela será sempre uma terra querida. Ontem: teve seu apogeu; hoje, tem a sua encantadora tradição. (CORREIO OFFICIAL, 24 fev. 1937, n. 3392).

Os partidários do governo entendiam que a única possibilidade para a outrora capital do Estado era vinculá-la a Goiânia, o que só seria possível por meio da sua colocação como o passado necessário, mas superado. Reconhecê-la como passado do lugar significava dignificá-la, reconhecer sua importância, mas, simultaneamente, desprender-se do compromisso de inseri-la nos meandros da modernidade. A Cidade de Goiás funcionaria como o contraponto à Goiânia: tradição $x$ modernidade.

Reconhece-se a adoção desse discurso pelo Estado, mas principalmente pelos moradores da cidade, que, do sentimento de abandono advindo do anacronismo com o tempo moderno, passam a cultivar o orgulho de representarem as raízes culturais de Goiás. Aos poucos, os vilaboenses 
voltaram a se sentir importantes e merecedores das alusões daqueles que admiravam aquele pedaço do sertão brasileiro.

Naquele momento, em meio ao discurso modernizador de Vargas, a proteção a cidades históricas como Ouro Preto e a fundação do Serviço do Patrimônio Histórico e Artístico Nacional (SPHAN) descortinam outras possibilidades para os núcleos urbanos coloniais, não os alijando desse processo. No discurso modernista brasileiro iniciado na década anterior, as raízes nacionais tornaram-se fundamentais para criar uma modernidade própria. Nesse caso, a história e a tradição inserem-se no percurso transformador das estruturas sociais brasileiras.

No limiar dos anos de 1940, o jornal Cidade de Goiaz acenava a assimilação da antiga Vila Boa como monumento e a possibilidade de vinculá-la às atividades econômicas do turismo.

A cidade de Goiaz como centro turístico - Castro Costa

[...] Cidade-evolução, cidade-monumento, cidade-cultura, cidade-mãe, enfim, Goiaz está presente em todas as emoções cívicas de nossa história, desde as remotas quadras da tumultuária colonização lusa até a edificação de Goiânia. A sua própria sucessora Pedro Ludovico a concebeu dentro dos espessos paredões de seu Palácio do Conde dos Arcos, de cujos compartimentos assimétricos e de desenhos bizarros partiam as ordens e os decretos que iriam influir na vida de todos os quadrantes do território goiano.

Esse sentimento de valorização pessoal que cada indivíduo naquela cidade possui é defensável e traduz um pormenor por certo de sadio patriotismo, uma vez que não existe patriotismo de boas raízes sem o natural apego do homem ao lar [...].

Essas razoes recomendam Goiaz como um excelente ponto de turismo, porque ali se sente plenamente o brasileiro típico do Estado, [...]. Acho, com a maior sinceridade, que à antiga capital devem ser encaminhados os turistas que venham ter ao Estado, os quais, após sentir a vibração trepidante de Goiânia e Anápolis, encontrarão na cidade de Anhanguera algo que muito podem se orgulhar os goianos. [...].

Para se conseguir esse objetivo [...], há uma coisa para se fazer: intensificar o intercambio social entre a velha e a nova capital - duas cidades que tem que marchar de mãos dadas, no futuro. (CIDADE DE GOIAZ, 10 mar. 1940, n.75).

Como monumento, a Cidade de Goiás seria eleita como um lugar de memória para os goianos. Goiânia começava a ofuscar a velha capital que deveria se institucionalizar como monumento histórico para que não fosse esquecida. O esforço iniciava-se com a aceitação dos goianos pela eleição da Cidade de Goiás como representação identitária, o que significava o fortalecimento da ordem estabelecida. Essas ideias veiculadas pelos jornais antecipavam a ação do SPHAN na cidade bandeirista, que se iniciou em 1950, com o tombamento das suas igrejas setecentistas (MINISTÉRIO DA CULTURA, 1994). Em Goiás, o SPHAN fez seu primeiro tombamento em 1941, a Igreja Matriz de Nossa Senhora do Rosário, em Pirenópolis. A partir do reconhecimento dos seus bens históricos e artísticos, Goiás passou a compartilhar dos parâmetros 
institucionais da identidade nacional, o que o integra a um circuito de interesses que extrapolam o âmbito local.

No bojo de tal discurso, reconhece-se outra antecipação expressa nesse artigo, que é a articulação entre a monumentalização urbana e o turismo. Essa prática ocorria informalmente e passou a ser incentivada pela legislação federal a partir do final da década de 1960 e início de 1970, como forma de garantir a preservação dos monumentos eleitos (RODRIGUES, 2001).

Para a concretização da atividade econômica do turismo na Cidade de Goiás, o artigo sugeria a sua aliança com Goiânia e Anápolis - uma cidade a pouca distância da capital, servida por via férrea, considerada um grande centro comercial regional -, o que indica a indissociabilidade entre a modernidade e a tradição. Na visão dos defensores dessa ideia, o novo não abandona o velho, mas o acompanha de mãos dadas.

Passados cinco anos, o mesmo jornal continuava esperançoso no futuro da cidade substituída. Goiânia era enaltecida - "brilhante cidade que Pedro Ludovico imaginou, creou, transformou em admirável realidade para nosso orgulho e envaidecimento” -, mas o objetivo era soerguer as esperanças dos vilaboenses: “precisamos conservar e faze-la, hora a hora, desenvolverse, prosperar e se engrandecer. Nada nos falta. Temos tudo para uma vida próspera e feliz e confiamos, acima das contingências, num grande futuro e inusitado alvorecer no próximo amanhã que vem a galope no próximo encontro” (CIDADE DE GOIAZ, 28 jan. 1945, n. 259).

No mesmo jornal, um artigo do primeiro prefeito de Goiânia se sobressai, por reconhecer o valor da história da antiga capital e conferir o seu renascimento às atividades rurais, que ativam o comércio e, consequentemente, o progresso. Borges reconhece cidade e campo, modernidade e história, estado e município como oposições complementares no processo de modernização.

\section{Hontem e hoje - Venerando de Freitas Borges}

[...] Hoje, passados tantos anos em que se procurou estabelecer dissídio entre Goiaz e Goiania - fruto de incompreensão - as duas cidades se irmanam no sentimento comum de elevar sempre o nome do Estado.

Sobre a lendária cidade de Bueno há sempre o que dizer, o que estudar, tal o valor de suas tradições, a variedade, a multiplicidade de tons de que se reveste o portentoso quadro de sua admirável topografia e a influencia de personalidades de relevo que ali nasceram; tal a contribuição inestimável de sua gente na formação dos costumes, na estruturação do cabedal moral da família goiana. As ruas sinuosas, apertadas, com seu casario branco, colonial, esparramado pelas encostas e ribanceiras do rio Vermelho, guardam a lembrança do áureo período da mineração, [...]. E Goiaz cresceu a sombra da influencia governamental, certa de que a sua vida estava na dependência direta e exclusiva do fator politico - que era a expressão maior. $\mathrm{E}$ assim, descuidada dos acontecimentos que o futuro lhe pudesse trazer, não se deu ao trabalho de organizar em bases seguras a sua economia. Mudada a Capital, houve o desânimo das horas de confusão dos espíritos, 
atribulados estes com a propaganda soez e subversiva que então lavrava. E já são decorridos 8 anos. Muitos fatos, muita coisa houve nesse período e agora nova e esperançosa rota se abre para os destinos da velha e querida Goiaz. É que animados de novos propósitos, [...], os habitantes do prospero município se lançaram na luta, dispostos a compensar pelo trabalho continuado, pelo espírito de cooperação, a perda do cetro que sustentou por dois séculos.

[...] é interessante constatar que, enquanto sofria a Sede colapso com a transferência do governo para Goiânia, a zona rural se valorizava, ou melhor, atraia fazendeiros de outras bandas. Com o incremento da produção agrícola, verificou-se o fenômeno comum a toda cidade sertaneja. Cresceu o comercio, ativaram-se todas as iniciativas, determinando um ritmo novo na vida da velha cidade. Por outro lado, cumpre destacar o apoio que o Interventor Pedro Ludovico vem dando à administração do Prefeito Divino Oliveira, [...]. Por tudo isso, vê-se que Goiaz atravessa uma fase de reconstrução e caminha para frente, confiada no seu lastro, que é considerável, e na ação patriótica de seus filhos. Que os que ali mourejam, se juntem no esforço comum de bem servi-la e, estamos certos, o seu progresso se afirmará. (CIDADE DE GOIAZ, 28 jan. 1945, n. 259).

Observa-se que a opinião de alguém de fora não se limita a referenciar os valores tradicionais ligados à cidade, mas aponta a relevância daqueles presos ao mundo rural, ainda que desemboquem nas transformações urbanas e influenciem nelas. Nesse sentido, o prefeito da nova capital afirma a posição de Goiânia como ícone da modernidade e sugere a eleição da Cidade de Goiás como símbolo do passado, mas passível de transformação pelo presente.

\section{Considerações finais}

O percurso pelos periódicos permite perceber as sensibilidades de um tempo em Goiás. Tempo de mudança. A mudança da capital significava muito mais do que a transferência do governo estadual. Essa mudança trazia implícito o desejo do novo em oposição ao antigo. A morfologia de uma nova cidade sobrepunha-se àquela advinda de séculos anteriores, indicando a inauguração de estruturas políticas, econômicas, sociais, diferentes das existentes.

Como tudo que desestabiliza uma situação já sedimentada, a criação de Goiânia também provocou muitas reações aos que foram destronados do seu lugar de centro de poder. Tempo de rancores, ressentimentos, desesperança. As manifestações de descrédito a Goiânia expressavam o desejo do retorno ao passado. A constatação da irreversibilidade do tempo suscita sentimentos de desamparo que se transforma em esperança. Tempo de sobrevivência. Tempo da história. Constróise a consonância entre o novo e o antigo.

O tempo passou e comprovou que a invenção da Cidade de Goiás como cidade monumento deu certo. As décadas de esquecimento favoreceram a manutenção da morfologia urbana e arquitetônica, impulsionando as várias invenções que se sucederam até culminar com a eleição da 
cidade como patrimônio da humanidade em 2001. A mobilização da sociedade civil, incentivada pelas esferas governamentais, ilustra a superação do passado de abandono, e sugere o apoio ao ressurgimento da cidade por meio da sua morfologia e de suas tradições como meio de posicionamento no mundo contemporâneo. Tempo de memória. Tempo de invenção.

\section{Referências}

CARENA, C. Ruína e Restauro. In: Enciclopédia Einaudi. Porto: Imprensa Nacional; Casa da Moeda, 1984, p.107-129.

CHAUL, N. F. Caminhos de Goiás: da construção da decadência aos limites da modernidade. Goiânia: Ed. UFG, 1997.

CUNHA NETO, O. Álbum de Fotografias sobre o Planejamento e Construção da Cidade de Goiânia: edição comemorativa - 1935-1995. Rio Verde, GO: Gráfica do Instituto de Assistência a Menores de Rio Verde, 1995.

DELGADO, A. Goiás: a invenção da cidade "Patrimônio da Humanidade”. Horizontes Antropológicos, Porto Alegre, v.11, n. 23, jan/jun 2005. Disponível em: <www.scielo.br.> Acesso em: abr. 2007.

GOMIDE, C. H. Centralismo político e tradição histórica. 1999. Dissertação (Mestrado em História) - Universidade Federal de Goiás, Goiânia, 1999.

Cidade de Goiás: da idéia de preservação à valorização do patrimônio - a construção da imagem de cidade histórica (1930-1978). In: CHAUL, N. F.; SILVA, L. S. D. da (Org.). As cidades dos sonhos: desenvolvimento urbano em Goiás. Goiânia: Ed. UFG, 2004. p. 101-136.

LEPETIT, B. Das capitais às praças centrais: mobilidade e centralidade no pensamento econômico Francês. In: SALGUEIRO, H. A. (Org.). Cidades capitais do século XIX: racionalidade, cosmopolitismo e transferência de modelos. São Paulo: Ed. USP, 2001. p. 41-65.

MELLO, M. M. de. Goiânia: cidade de pedras e de palavras. Goiânia: Ed. UFG, 2006.

MINISTÉRIO DA CULTURA, IPHAN. Bens móveis e imóveis inscritos nos Livros do Tombo do Instituto do Patrimônio Histórico e Artístico Nacional. 4. ed. rev. ampl. Rio de Janeiro: IPHAN, 1994.

OLIVEIRA, A. M. V. de. Uma ponte para o mundo goiano do século XIX: um estudo da casa meiapontense. Goiânia: AGEPEL, 2001.

PESAVENTO, S. J. Na contramão da vida: razões e sensibilidades dos filhos malditos de Deus (Antônio Rasgado, Benjamin o Degolador, João Foguista). In: ERTZOGUE, M. H.; PARENTE, T. G. (Orgs.). História e sensibilidade. Brasília: Paralelo 15, 2006. p. 161-177.

RODRIGUES, M. Preservar e consumir: o patrimônio histórico e o turismo. In: FUNARI, P. P.; PINSKY, J. (Org.). Turismo e patrimônio cultural. São Paulo: Contexto, 2001. p. 13-24. 


\section{Periódicos (jornais)}

A COLLIGAÇÃO, 30 set. 1934, n. 6.

A COLLIGAÇÃO, 4 out. 1934, n.7.

A COLLIGAÇÃO, 29 set. 1935, n.41.

A COLLIGAÇÃO, 13 out. 1935, n. 42.

A COLLIGAÇÃO, 10 nov. 1935, n. 45.

A COLLIGAÇÃO, 8 dez. 1935, n. 47.

A COLLIGAÇÃO, 19 dez. 1935, n. 48.

A COLLIGAÇÃO, 4 jan. 1936, n. 49.

CIDADE DE GOIAZ, 19 jun. 1938, n.1.

CIDADE DE GOIAZ, 10 mar. 1940, n.75.

CIDADE DE GOIAZ, 28 jan. 1945, n. 259.

CORREIO OFFICIAL, 12 dez. 1933, s./n.

CORREIO OFFICIAL, 19 fev. 1937, n. 3370.

CORREIO OFFICIAL, 9 jan. 1937, n. 3360.

CORREIO OFFICIAL, 24 fev. 1937, n. 3392.

GOIÂNIA, 11 jun. 1936, n. 3.

O SOCIAL, 16 fev. 1934, n. XXIII.

VOZ DO POVO, 4 mar. 1934, n. 319.

VOZ DO POVO, 16 abr. 1933, n. 277

VOZ DO POVO, 2 jun. 1933, n. 281.

Recebido em 08/02/2011

Aprovado em 16/03/2011 